\title{
Commentary \\ Challenging the rationale of routine vasopressor therapy for management of hypotension
}

Max Harry Weil and Wanchun Tang

Weil Institute of Critical Care Medicine, Rancho Mirage, CA 92270, USA

Corresponding author: Max Harry Weil, weilm@weiliccm.org

Published: 14 August 2009

This article is online at http://ccforum.com/content/13/4/179

(c) 2009 BioMed Central Ltd

See related research by Dubin et al., http://ccforum.com/content/13/3/R92

\begin{abstract}
There is persuasive evidence, including the present report by Dubin and colleagues, of a dissociation between increases in arterial pressure produced by vasopressor agents and improvement in microvascular perfusion and delivery of vital substrates. Especially in settings of septic shock, the current routine administration of adrenergic vasopressor therapy therefore may fail to reverse the primary defect.
\end{abstract}

The largely universal treatment of hypotension associated with cardiogenic, distributive (septic) and obstructive shock states with adrenergic vasopressor agents in the past century is based on the goal of restoring blood pressure to more normal levels. However, the evidence that such treatment improves outcomes is assumed, and, as yet, is not backed by the security of proven value based on controlled clinical trials. The current focus of treatment of shock states, including septic shock, has been almost entirely on the macrocirculation, including heart rate and rhythm, arterial pressure, cardiac filling pressures and cardiac output, arterial and mixed venous oxygen saturation, and calculated oxygen delivery and utilization. These hemodynamic variables are used to guide fluid repletion and vasopressor-inotropic interventions in an effort to optimize their values.

With the recent availability of non-invasive techniques for visualization of the microcirculation in both clinical and experimental settings, there is now persuasive evidence of a dissociation between cardiac output and aortic/arterial pressures and the extent to which flow is delivered to the capillary exchange vessels, specifically in settings of septic shock $[1,2]$. Despite achieving numerically more normal systemic flow and oxygen delivery, the defect at the microcirculation level is such that capillary blood flow fails to be sustained. We suspect, but have not proven, that there is shunting between pre-capillary arterioles and post-capillary venules, accounting for the prominent increases in mixed venous oxygen saturation that are typical of the initial stages of septic shock. If vasopressor drugs such as norepinephrine are administered to achieve more normal levels of arterial pressure, they may not favorably affect capillary perfusion and, thereby, mitigate the failure of oxygen and other substrate delivery and exchange. In the present issue of Critical Care, Dubin and colleagues [1] measured effects of norepinephrine on the microcirculation in the sublingual mucosa of patients with hypotension in settings of sepsis. The authors confirmed the previously reported microcirculatory abnormalities in their patients with septic shock [1]. When norepinephrine was administered so as to increase mean arterial pressure in increments from 65 to $85 \mathrm{mmHg}$, there was no improvement in capillary perfusion in the sublingual mucosa and sometimes even decreases.

These observations are admittedly preliminary and were derived from a relatively small and diverse population of patients with microcirculatory measurements limited to a single sublingual site, although there is evidence that such decreases in sublingual mucosal capillary flows are reflective of decreases in organ perfusion [3]. These findings may also be viewed in the context of a recent report from our group in which adrenergic drugs had adverse effects on the microcirculation. In settings of cardiopulmonary resuscitation, for instance, the administration of epinephrine decreased microcirculatory flow to the cerebral cortex and increased the severity of cortical ischemia, even though arterial pressure and even large vessel arterial flow were increased [4].

We are reminded of yesteryear, when purgatives and blood letting were the established therapies. In the 18th and even the 19th centuries, these were intended to rid the patient's body of the injurious invaders in the blood and the gut responsible for disease. These hastened the demise of even our historically most notable leader, first President of the United States, George Washington, who was purged and 
from whom more than one half of his estimated blood volume was removed for treatment of what was more likely streptococcal pharyngo-epiglotitis [5]. Current ethics constraints are such that a challenge to established practices, including the use of adrenergic vasopressor agents in life threatening settings, including cardiopulmonary resuscitation, are not eligible for objective review, including placebo controls. Accordingly, the objective evidence contributed by Dubin and associates that points to a lack of benefit from vasopressor agents in the management of hypotension and raises the potential for adverse effects may favor optimism that the need for objectively controlled, randomized re-examination of the roles of these so widely used vasopressor and inotropic interventions will be ethically sanctioned.

\section{Competing interests}

The authors declare that they have no competing interests.

\section{References}

1. Dubin A, Pozo MO, Casabella CA, Pálizas F Jr, Murias G, Moseinco MC, Kanoore Edul VS, Pálizas F, Estenssoro E, Ince C: Increasing arterial blood pressure with norepinephrine does not improve microcirculatory blood flow: a prospective study. Crit Care 2009, 13:R92.

2. DeBacker D, Creter J, Prewer JC, Dubois MJ, Vincent JL: Microvascular blood flow is altered in patients with sepsis. $A m J$ Resp Crit Care Med 2002, 166:98-104.

3. Jin X, Weil MH, Sun S: Decreases in organ blood flows associated with increases in sublingual $\mathrm{PCO}_{2}$ during hemorrhagic shock. J Appl Physiol 1998, 85:2360-2364.

4. Ristagno G, Sun S, Tang W, Castillo C, Weil MH: Effects of epinephrine and vasopressin on cerebral microcirculatory flows during and after cardiopulmonary resuscitation. Crit Care Med 2007, 35:2145-2149.

5. Vadakan VV: The asphyxiating and exsanguinating death of President George Washington. Permanente J 2004, 8:76-79. 